DOI: $10.15593 / 2224-9982 / 2017.48 .07$

УДК 621.763:621.454.3

\author{
И.Б. Шендеров, Б.А. Воскресенский, А.П. Гуляйкин, И.В. Сысоева \\ АО «Пермский научно-исследовательский технологический институт», Пермь, Россия
}

\author{
ИДЕНТИФИКАЦИЯ ТЕХНОЛОГИЧЕСКИХ РИСКОВ \\ И ПОВЫШЕНИЕ КАЧЕСТВА УГЛЕРОД-УГЛЕРОДНЫХ МАТЕРИАЛОВ
}

\begin{abstract}
Приводятся результаты исследования, выполненного с целью повышения качества изготовления деталей из углерод-углеродных композиционных материалов. Технология изготовления включает жидкостное насыщение углеволоконного каркаса углеводородным связующим - каменноугольным пеком - и последующую графитацию. Полученные по этой технологии композиционные материалы обладают уникальными свойствами, в том числе при высоких температурах и нагрузках, но их качество чувствительно к свойствам сырья, получаемого из природных материалов. Целью описываемой работы являлось обеспечение стабильности свойств углерод-углеродных материалов в производстве, в частности за счет идентификации и исключения факторов, повышающих риски. Полученные результаты основаны на длительном мониторинге технологического процесса и продукции, включая регрессионный анализ промышленных данных. Прямая связь между сертификатными характеристиками пека и физико-механическими свойствами готового продукта не установлена. Особенностью поставленной задачи в условиях мелкосерийного производства является доступность только относительно небольшой выборки данных, что ограничивает возможность статистических методов. Для этих условий предложен способ идентификации характеристик сырья, совокупность которых может повысить риск получения несоответствующей продукции. Разработана математическая модель кумулятивного влияния свойств сырья на качество продукта и получена зависимость для анализа рисков. Выделенные для расчета характеристики выбраны по уровню корреляции с оценкой риска получения несоответствующей продукции. Таким образом выбраны четыре из шести сертификатных характеристик и построена линейная форма, предлагаемая в качестве критерия соответствия используемого каменноугольного пека.
\end{abstract}

Ключевые слова: углерод-углеродный композиционный материал, каменноугольный пек, характеристики, качество, идентификация, расчет, итерации, коэффрициенты влияния, критерий, линейная регрессия, риск.

\author{
I.B. Shenderov, B.A. Voskresenskii, A.P. Guliaikin, I.V. Sysoeva \\ JSC “Perm Scientific Research Technological Institute", Perm, Russian Federation
}

\title{
IDENTIFICATION OF TECHNOLOGICAL RISKS AND IMPROVEMENT OF QUALITY OF CARBON-CARBON COMPOSITES
}

\begin{abstract}
It is presented the results of research carried out with the aim of improving the quality of the manufacture of parts from carbon-carbon composites. Used in this case, the production method is based on the impregnation of the frame from carbon fiber liquid coal-tar pitch and a graphitization of the composition. Composite materials obtained by this technology have unique properties, including under high temperatures and loads, but their quality is sensitive to the properties of raw from natural materials. The aim of the work was to ensure the stability of the properties of carbon-carbon materials in the production, in particular by identifying and addressing the factors that increase the risks. The results are based on long-term monitoring of the process and products, including using regression analysis of production data. Direct relationship between certificate data of raw and physico-mechanical properties of the finished product is not determined. The peculiarity of the problem in small-scale production is the availability of only a relatively small sample of data, which limits the possibility of statistical methods. For these conditions there is provided a method of identifying characteristics of the raw material, the totality of which can increase the risk of production of unsuitable products. It was developed the mathematical model of the cumulative influence of properties of raw material on the quality of the product and the dependence for calculation of risk. Before inclusion in the calculation the characteristics of the raw materials were ranked according to the degree of influence on risk assessment. Thus it was selected 4 characteristics from 6 which included in the certificate. It was constructed a linear form, which is a fitting criterion of used coal tar pitch.

Keywords: carbon-carbon composite material, coal pitch, characteristics, quality, identification, calculation, iterations, influence coefficients, criterion, linear regression, risk.
\end{abstract}

Развитие техники в последние десятилетия потребовало создания новых материалов, обладающих уникальными свойствами, которыми не обладают традиционные металлы, полимеры и другие виды материалов. Такими материалами стали композиционные материалы, среди которых углеродные занимают особое положение [1-5]. Один из способов получения углерод- 
углеродного композиционного материала (УУКМ) [6-9] основан на пропитке объемноармирующего углеволокнистого $[10,11]$ каркаса жидким углеродсодержащим составом с последующей графитацией композиции при высокой температуре [12-14]. В АО ПНИТИ для получения УУКМ [15] используется каменноугольный пек [16-19]. Как отмечено в работе [20], в нашей стране сырьевая база таких материалов ограничена в основном пеками каменноугольного происхождения, выпускаемыми коксохимическими предприятиями. Качество этих пеков часто не соответствует стандартам, разработанным для электродных пеков, применяемых для производства композиционных углеродных материалов, а также требованиям, определяющим, в конечном счете, эксплуатационные характеристики конечной углеродной продукции. Длительное время в АО ПНИТИ использовали каменноугольный пек производства ОАО «Северсталь». В связи с изменением номенклатуры продукции этого предприятия был осуществлен переход на продукцию другого поставщика. Проведенные исследования, завершившиеся изготовлением УУКМ из пека выбранного поставщика, позволили продолжить серийное производство.

С целью обеспечения стабильного качества продукции в течение 2015 г. был организован мониторинг качества УУКМ. В производство было запущено 15 промышленных партий пека, соответствующих установленным требованиям. При анализе результатов испытания образцов готовой продукции было установлено, что при стабильном технологическом процессе отмечены случаи снижения качества по нескольким физико-механическим характеристикам, но в пределах, допускаемых техническими условиями на материал. Эти случаи были квалифицированы как связанные с особенностями нескольких партий пека. Свойства пека зависят от исходного сырья, особенностей технологии и прочих факторов.

Сертификатные характеристики сырья указаны ниже. В табл. 1 приводятся сертификатные данные всех использованных в течение года партий пека. Сопоставление совокупностей партий, различающихся по характеристикам готовой продукции (табл. 2), учитывая существенно разные количества партий в каждой подгруппе, не позволяет определить возможную причину отклонения.

\section{Характеристики сырья}

\begin{tabular}{|l|l|}
\hline$i$ & \multicolumn{1}{|c|}{ Наименование характеристики } \\
\hline 1 & Температура размягчения, ${ }^{\circ} \mathrm{C}$ \\
\hline 2 & Массовая доля золы, $\%$ \\
\hline 3 & Массовая доля влаги, $\%$ \\
\hline 4 & Массовая доля коксового остатка, $\%$ \\
\hline 5 & Массовая доля веществ, нерастворимых в толуоле, $\%$ \\
\hline 6 & Массовая доля веществ, нерастворимых в хинолине, $\%$ \\
\hline
\end{tabular}

Прямая связь между сертификатными (указываемыми в сертификате в соответствии с требованиями технических условий) характеристиками пека и физико-механическими свойствами готового продукта отсутствует.

Целью настоящей работы являлась идентификация сырья (каменноугольного пека), определение совокупности характеристик, сочетание которых может привести к повышению риска получения несоответствующей продукции, и разработка необходимых предупреждающих мероприятий. Решаемая задача имеет некоторую неопределенность: сертификатные характеристики сырья нельзя однозначно считать достаточными и взаимно независимыми (оценки коэффициентов парной корреляции приведены в табл. 3), размер выборки исходных данных недостаточен для надежного использования статистических методов [21]. 
Таблица 1

Характеристики партий сырья

\begin{tabular}{|c|c|c|c|c|c|c|c|}
\hline \multirow{2}{*}{$j$} & \multicolumn{6}{|c|}{$i$} & \multirow{2}{*}{$\begin{array}{c}\text { Оценка партии } \\
\text { сырья }\end{array}$} \\
\hline & 1 & 2 & 3 & 4 & 5 & 6 & \\
\hline 1 & 141 & 0,15 & 1,1 & 56 & 47 & 29 & Нормально \\
\hline 2 & 139 & 0,17 & 1,0 & 58 & 50 & 30 & Нормально \\
\hline 3 & 138 & 0,15 & 0,9 & 54 & 48 & 23 & Нормально \\
\hline 4 & 140 & 0,15 & 1,0 & 50 & 48 & 30 & Критично \\
\hline 5 & 145 & 0,40 & 0,6 & 56 & 56 & 17 & Критично \\
\hline 6 & 142 & 0,40 & 0,5 & 61 & 54 & 36 & Критично \\
\hline 7 & 142 & 0,19 & 0,5 & 58 & 48 & 27 & Критично \\
\hline 8 & 143 & 0,19 & 0,6 & 56 & 47 & 23 & Нормально \\
\hline 9 & 144 & 0,48 & 1,1 & 60 & 49 & 30 & Нормально \\
\hline 10 & 137 & 0,22 & 1,0 & 59 & 48 & 23 & Нормально \\
\hline 11 & 134 & 0,13 & 1,1 & 60 & 48 & 25 & Нормально \\
\hline 12 & 137 & 0,05 & 1,0 & 61 & 49 & 31 & Нормально \\
\hline 13 & 140 & 0,02 & 1,0 & 61 & 48 & 31 & Нормально \\
\hline 14 & 138 & 0,23 & 1,0 & 60 & 47 & 31 & Нормально \\
\hline 15 & 141 & 0,20 & 1,0 & 64 & 53 & 34 & Нормально \\
\hline
\end{tabular}

Таблица 2

Сопоставление характеристик партий сырья

\begin{tabular}{|c|l|c|c|c|c|c|c|}
\hline \multirow{2}{*}{$j$} & \multicolumn{1}{|c|}{ Параметр } & \multicolumn{7}{c|}{$i$} \\
\cline { 3 - 8 } & & 1 & 2 & 3 & 4 & 5 & 6 \\
\hline \multirow{2}{*}{$8-3,15$} & Нижняя граница & 134 & 0,02 & 0,6 & 54 & 47 & 23 \\
\cline { 2 - 8 } & Верхняя граница & 144 & 0,48 & 1,1 & 64 & 53 & 34 \\
\cline { 2 - 8 } & Среднее значение & 139 & 0,18 & 0,98 & 59 & 48,5 & 28 \\
\cline { 2 - 8 } & Среднеквадратическое отклонение & 2,90 & 0,12 & 0,14 & 2,83 & 1,75 & 3,95 \\
\hline \multirow{3}{*}{$4-9$} & Нижняя граница & 140 & 0,15 & 0,5 & 50 & 48 & 17 \\
\cline { 2 - 8 } & Верхняя граница & 145 & 0,4 & 1,0 & 61 & 56 & 36 \\
\cline { 2 - 8 } & Среднее значение & 142 & 0,29 & 0,7 & 56 & 52 & 28 \\
\cline { 2 - 8 } & Среднеквадратическое отклонение & 2,06 & 0,13 & 0,24 & 4,65 & 4,12 & 7,94 \\
\hline
\end{tabular}

Таблица 3

Коэффициенты парной корреляции характеристик сырья

\begin{tabular}{|c|c|c|c|c|c|c|}
\hline \multirow{2}{*}{$i$} & \multicolumn{7}{|c|}{$i$} \\
\cline { 2 - 7 } & 1 & 2 & 3 & 4 & 5 & 6 \\
\hline 1 & 1,00 & 0,62 & $-0,54$ & $-0,13$ & 0,46 & $-0,07$ \\
\hline 2 & 0,62 & 1,00 & $-0,34$ & 0,06 & 0,55 & $-0,08$ \\
\hline 3 & $-0,54$ & $-0,34$ & 1,00 & 0,11 & $-0,43$ & 0,22 \\
\hline 4 & $-0,13$ & 0,06 & 0,11 & 1,00 & 0,25 & 0,46 \\
\hline 5 & 0,46 & 0,55 & $-0,43$ & 0,25 & 1,00 & 0,00 \\
\hline 6 & $-0,07$ & $-0,08$ & 0,22 & 0,46 & 0,00 & 1,00 \\
\hline
\end{tabular}


Качество готовой продукции из УУКМ характеризуется достаточно большим набором физико-механических характеристик. Выявление причин возникшей проблемы путем расчета корреляций всех характеристик УУКМ с характеристиками пека из-за явной недоступности больших выборок и больших ожидаемых доверительных интервалов сразу было признано неэффективным. Кроме того, свойства сырья - каменноугольного пека - характеризуются не значениями определенных физико-химических величин, а достаточно косвенно, интегрально, в том числе растворимостью компонентов в стандартных растворителях и величиной несгораемого остатка. В этих условиях задача исследования была поставлена как изучение процесса с формализованными входами и бинарным откликом «хорошо» - «плохо». Если весь комплекс контролируемых свойств УУКМ находится в заданном диапазоне значений, расчетный риск равен нулю, если хотя бы одна характеристика вышла на грань допустимого, риск равен единице. В такой постановке при небольшой доступной выборке опытных данных корреляционным анализом удалось получить количественные оценки проблемы, а не ограничиваться обычным описательным анализом. Для комплексной оценки качества (пригодности для использования по назначению) сырья необходимо найти (если таковая существует) величину, рассчитываемую по совокупности свойств сырья, и критерий - правило отнесения продукции к соответствующей или несоответствующей.

Формализуется задача следующим образом. Имеется $n$ сертификатных характеристик $x_{i}$ $(i=1,2, \ldots, n)$, приведенных выше, и $m$ практических реализаций (см. табл. 1). Для идентификации рисков предлагается использовать уравнение регрессии (в первом приближении - линейной), аппроксимирующее бинарную функцию, принимающую значение 0 для успешных реализаций, и значение 1 - для реализаций, рассматриваемых как критические:

$$
R=c+\sum_{i=1}^{n} k_{i} x_{i}
$$

Здесь $c$ - постоянная составляющая; $k_{i}, i=1,2, \ldots, n$ - коэффициенты влияния характеристик.

Количество «успешных» реализаций - $m_{1}, j \subset M_{1}$, «критических» - $m_{2}, j \subset M_{2}$, $m_{1}+m_{2}=m ; j-$ условный номер партии сырья.

Функцию (1) можно считать приемлемой, если ее значения для подмножеств - «успешных» и «критических» реализаций - будут различаться. Например, при среднем уровне значений до 0,5 значение этой функции для критических партий должно быть соизмеримо с единицей.

Физический смысл функции $R$ - оценка риска получения несоответствующей продукции. Таким образом, критерием качества (пригодности сырья) будет являться малое значение оценки: $R<0,5$.

Поставленная задача решалась по следующему итеративному алгоритму:

- строится линейная форма $R$ для всей выборки данных табл. 1 ;

- если значения $R$ для выделенных экспертами подмножеств $M_{1}$ и $M_{2}$ партий сырья неразличимы, то в рассматриваемой постановке поставленная задача решения не имеет;

- если по значениям $R$ подмножества уверенно различаются, то характеристики сырья ранжируют по уровню влияния на величину $R$;

- проводят расчет формы $R$ для усеченной выборки - исключают данные, относящиеся к характеристике сырья с наименьшим влиянием на результат;

- если подмножества $M_{1}$ и $M_{2}$ различаются по значениям $R$, продолжают процесс расчета. В противном случае в качестве решения принимают результаты предыдущего шага расчета.

Параметры уравнения (1) определяли по условию наименьших квадратов:

$$
\sum_{j \subset M_{1}} R_{j}^{2}+\sum_{j \subset M_{2}}\left(R_{j}-1\right)^{2} \rightarrow \min
$$

которое, с учетом выражения (1), приводит к системе линейных уравнений 


$$
\sum_{i=1}^{n+1} a_{p i} k_{i}=b_{p}, p=1,2, \ldots, n+1
$$

где $k_{n+1}=c ; \quad a_{p i}=\sum_{j \subset M} x_{p j} x_{i j} ; \quad b_{p}=\sum_{j \subset M_{2}} x_{p j}$ при $p=1,2, \ldots, n ; \quad a_{n+1, i}=\sum_{j \subset M} x_{i j} ; a_{n+1, n+1}=m ;$ $b_{n+1}=m_{2} ; M_{1}-$ множество партий сырья, по которым не возникло вопросов (количество таких $\left.m_{1}=11\right) ; M_{2}-$ множество партий сырья, при использовании которых выявились отклонения от ожидаемых результатов (количество партий $m_{2}=4, m_{1}+m_{2}=m$ ).

Уравнения (2) решались по компактной схеме исключения [22].

Ранжирование параметров - характеристик сырья по степени влияния на результаты расчета - проводилось в соответствии с табл. 2. Степень влияния $q_{i}$ оценивалась как величина произведения абсолютной величины коэффициента влияния $k_{i}$ на величину интервала изменения значения характеристики:

$$
q_{i}=\left|k_{i}\right|\left[\max _{j \subset M}\left(x_{i j}\right)-\min _{j \subset M}\left(x_{i j}\right)\right] .
$$

Результаты оценки приведены в табл. 4.

Таблица 4

Степень влияния характеристик сырья на результаты расчета

\begin{tabular}{|c|c|c|c|}
\hline \multirow{2}{*}{$i$} & \multicolumn{3}{|c|}{ Учитываемые характеристики $(i)$} \\
\cline { 2 - 4 } & $1-6$ & $1,3-6$ & $3-6$ \\
\hline 1 & 0,2447 & 0,1018 & - \\
\hline 2 & 0,1531 & - & - \\
\hline 3 & 0,5883 & 0,5761 & 0,5375 \\
\hline 4 & 0,4662 & 0,4577 & 0,4406 \\
\hline 5 & 0,1975 & 0,2174 & 0,2012 \\
\hline 6 & 0,2140 & 0,2057 & 0,1984 \\
\hline
\end{tabular}

При следующем расчете исключалась характеристика с наименьшим уровнем влияния. Последовательно исключались из рассмотрения характеристики с номерами 2 и 1. При дальнейшем уменьшении числа учитываемых характеристик партии сырья становились неразличимыми по параметру $R$ (см. табл. 1).

Результаты расчета приведены в табл. 5. Рамкой из жирных линий выделена область значений характеристик сырья, в которой значения оценки риска получения несоответствующей продукции $R>0,5$.

В результате выполненного исследования выявлена совокупность характеристик сырья, сочетание значений которых привело к существенному отклонению свойств полученного УУКМ от средних: в этих партиях хотя бы одна из контролируемых физико-механических характеристик УУКМ приближалась к границе допустимых значений. В пределах изменения значений характеристик сырья, использованного в течение 2015 г. (т.е. для значений характеристики 1 - от 134 до $145^{\circ} \mathrm{C}$, значений характеристики 2 - от 0,02 до $0,48 \%$ ), эти характеристики оказались незначимыми. Набольшее влияние оказывают характеристики $3,4,5$ и 6 , сочетания значений которых позволяют выделить партии сырья, экспертно при оценке готового продукта отмеченные как критические. Получено, что совокупность характеристик свойств сырья может, дополнительно к установленным сертификатным требованиям, оцениваться показателем

$$
R=1,404-1,075 x_{3}-0,073 x_{4}+0,067 x_{5}+0,028 x_{6} .
$$


Результаты расчета оценки риска $R$

\begin{tabular}{|c|c|c|c|c|c|}
\hline \multirow{2}{*}{$j$} & \multicolumn{4}{|c|}{ Учитываемые характеристики $(i)$} & \multirow{2}{*}{ Оценка партии сырья } \\
\cline { 2 - 4 } & $1-6$ & $1,3-6$ & $3-6$ & $3-5$ & \\
\hline 1 & 0,028 & 0,048 & 0,083 & 0,038 & Нормально \\
\hline 2 & 0,276 & 0,287 & 0,273 & 0,220 & Нормально \\
\hline 3 & 0,375 & 0,371 & 0,342 & 0,408 & Нормально \\
\hline 4 & 0,773 & 0,738 & 0,726 & 0,528 & Критично \\
\hline 5 & 0,853 & 0,866 & 0,884 & 1,108 & Критично \\
\hline 6 & 1,105 & 1,056 & 1,028 & 0,803 & Критично \\
\hline 7 & 0,576 & 0,586 & 0,591 & 0,581 & Критично \\
\hline 8 & 0,402 & 0,419 & 0,450 & 0,528 & Нормально \\
\hline 9 & $-0,050$ & $-0,126$ & $-0,048$ & $-0,052$ & Нормально \\
\hline 10 & $-0,076$ & $-0,111$ & $-0,133$ & 0,036 & Нормально \\
\hline 11 & $-0,177$ & $-0,200$ & $-0,257$ & $-0,117$ & Нормально \\
\hline 12 & 0,004 & 0,044 & 0,014 & $-0,009$ & Нормально \\
\hline 13 & $-0,148$ & $-0,072$ & $-0,053$ & $-0,073$ & Нормально \\
\hline 14 & 0,005 & $-0,039$ & $-0,047$ & $-0,083$ & Нормально \\
\hline 15 & 0,094 & 0,135 & 0,147 & 0,085 & Нормально \\
\hline
\end{tabular}

Рекомендуемый для производства критерий качества (пригодности сырья) $R<0,5$. Доверительные границы критерия по имеющимся данным не могут быть определены: выборки данных слишком малы, а характеристики сырья взаимозависимы (см. табл. 3), чтобы выявить законы распределения случайных значений характеристик. Использование в производстве сырья с малыми значениями оценки риска $R$ должно обеспечить стабильное качество УУКМ.

Соотношение между достаточно большим числом различающихся свойствами партий сырья (15) и числом характеристик (4), по значениям которых партии сырья были разделены на две группы, совпавшие с экспертными оценками партий, позволяет считать предложенную формализованную оценку достоверной.

С целью обеспечения стабильности качества изготавливаемых УУКМ мониторинг будет продолжен, а приведенные в настоящей работе результаты послужат для обсуждения с поставщиком возможности совершенствования технологии изготовления пека в выявленном направлении или целесообразности введения селективного отбора партий пека для изготовления УУКМ.

Предложенный метод идентификации может использоваться как один из инструментов регрессионного анализа при статистическом мониторинге качества продукции, особенно при наличии небольших выборок данных.

Таким образом, в результате выполненного исследования для обеспечения стабильности получения в производстве УУКМ с заданными свойствами:

а) предложен критерий качества (пригодности) сырья - каменноугольного пека определенной марки;

б) показана обоснованность предложенного критерия;

в) определены направления дальнейшего развитие работ по УУКМ: совершенствование технологии изготовления пека до устойчивого получения сырья с малыми значениями оценки риска $R$ или отбор для использования в производстве УУКМ только продукции, соответствующей предложенному критерию, что технически и экономически окажется эффективнее;

г) оценена возможность использования разработанного и предложенного в статье метода анализа (идентификации) в качестве исследовательского инструмента. 


\section{Библиографический список}

1. Проценко А.К., Колесников С.А. Разработка углерод-углеродных технологий и перспективы их развития // Научно-исследовательскому институту конструкционных материалов на основе графита 55 лет: сб. ст. - М.: Научные технологии, 2015. - С. 31-59.

2. Постнова М.В., Постнов В.И. Влияние температуры испытаний на усталостные свойства композиционных материалов на углеродной матрице // Изв. Самар. науч. центра РАН. - 2014. - Т. 16, № 6-2. C. 568-571.

3. Степашкин А.А., Мозолев В.В., Мостовой Г.Е. Оценка ресурса углерод-углеродных тормозных дисков авиаколес с учетом эволюции механических свойств материала // Автомобиле- и тракторостроение в России: Приоритеты развития и подготовка кадров: материалы 77-й междунар. науч.-техн. конф. ААИ. - М.: Изд-во МГТУ «МАМИ», 2012. - Кн. 5. - С. 93-115.

4. Дворецкий А.Э., Тащилов С.В., Фадеев В.А. О механическом уносе углеродных материалов // Космонавтика и ракетостроение. - 2016. - № 2(87). - С. 81-87.

5. Rehkopf J.A. Automotive carbon fiber composites. From evolution to implementation // SAE International. $-2011 .-128 \mathrm{p}$.

6. Uusitalo K. Designing in carbon fibre composites / Chalmers University of Technology. - Gothenburg, 2013. - $119 \mathrm{p}$.

7. Бейлина Н.Ю. Структурные преобразования пеков при взаимодействии с углеродными наполнителями: автореф. дис. ... д-ра техн. наук. - М., 2000. - 53 с.

8. Малько Д.Б. Способы совершенствования технологии объемно-армированных углерод-углеродных композиционных материалов: автореф. дис. ... канд. техн. наук. - М., 2000. - 31 с.

9. Ветошкин С.В., Долгодворов А.В., Сыромятникова А.И. Исследование объемной микроструктуры конструкционного углерод-углеродного композиционного материала и создание компьютерной 3Dмодели исследуемого образца // Вестник Пермского национального исследовательского политехнического университета. Аэрокосмическая техника. - 2014. - № 37. - С. 202-221.

10. Morgan P. Carbon fibers and their composites. - Boca Raton: Taylor \& Francis, 2005. - 1153 p.

11. Черненко Д.Н., Бейлина Н.Ю., Черненко Н.М. Изменение свойств углеродных волокон при высокотемпературной обработке // Участие молодых ученых в фундаментальных поисковых и прикладных исследованиях по созданию новых углеродных и наноуглеродных материалов: сб. тез. докл. шк.-семинара молодых ученых Центрального региона. 2-3 октября 2013 г. - Андреевка, 2013. - С. 48-51.

12. Manocha L.M., Manocha S. Co-graphitization of fibers and matrix in carbon-carbon composites with controlled interfaces // Ceramic Engineering and Science Proceedings. - 2002. - Vol. 23, № 3. - P. 411-418.

13. Особенности термопревращения каменноугольного пека в условиях низкотемпературной каталитической графитации при разных режимах термообработки / Г.П. Хохлова, Ч.Н. Барнаков, Л.М. Хицова, В.Ю. Малышева, 3.Р. Исмаилов // Вестник Кузбас. гос. техн. ун-та. - 2014. - № 1(101). - С. 89-94.

14. Трубин Ф.В., Докучаев А.Г., Чунаев В.Ю. Исследование влияния процессов высокотемпературной обработки на свойства углерод-углеродных материалов, предназначенных под парофазное силицирование // Известия вузов. Химия и химическая технология. - 2012. - № 6. - С. 48-51.

15. Теплозащитный эрозионностойкий углерод-углеродный композиционный материал и способ его получения: пат. 2386603 Рос. Федерация: МПК С 04 В 35/52, С 01 В 31/00, С 08 J 5/04 / Малафеев А.С., Воскресенский Б.А., Гуляйкин А.П., Нечаев И.А., Валеев Р.Р., Краснов Л.Л.; № 2007139204/04(042911); заявл. 24.10.2007; опубл. 20.04.2010, Бюл. № 12.

16. Marković V. Use of coal tar in carboncarbon composites // Fuel. - 1987. - Vol. 66, № 11. P. 1512-1515.

17. Обзор рынка пека каменноугольного в СНГ / ООО ИГ «Инфомайн». - М., 2015. - 105 с.

18. Влияние таллового масла и ультразвуковой обработки на получение пека из смолы полукоксования или антраценовой фракции / Ч.Н. Барнаков, С.Н. Вершинин, Г.П. Хохлова, А.В. Самаров // Кокс и химия. - 2015. - № 10. - С. 33-37.

19. Получение альтернативного связующего пека методом термохимической переработки углей / Е.Н. Маракушина, П.Н. Кузнецов, Ф.А. Бурюкин, С.С. Косицына // Фундаментальные исследования. 2015. - № 12 (ч. 3). - С. 474-479.

20. Бейлина Н.Ю. Особенности применения углеродных наноструктур в матрицах композиционных материалов // Углерод: фундаментальные проблемы науки, материаловедение, технология: сб. тез. докл. девятой междунар. конф. - М.: Троицк, 2014. - С. 53-57. 
21. Сухорученков Б.А. Анализ малой выборки. Прикладные статистические методы. - М.: Вузовская книга, 2010. - 384 с.

22. Корн Г., Корн Т. Справочник по математике. Для научных работников и инженеров. - М.: Наука, 1973. - 832 с.

\section{References}

1. Protsenko A.K., Kolesnikov S.A. Razrabotka uglerod-uglerodnykh tekhnologiy i perspektivy ikh razvitiya [Development of carbon-carbon technologies and prospect of their development]. Nauchno-issledovatelskomu institutu konstruktsionnykh materialov na osnove grafita - 55 let. Sbornik statey. Moscow, Nauchnye tekhnologii, 2015, pp. 31-59.

2. Postnova M.V., Postnov V.I. Vliyanie temperatury ispytaniy na ustalostnye svoystva kompozitsionnykh materialov na uglerodnoy matritse [Influence of temperature of tests on fatigue properties of composite materials with carbon matrix]. Izvestiya Samarskogo nauchnogo tsentra Rossiyskoy akademii nauk, 2014, vol. 16, no. 6-2, pp. 568-571.

3. Stepashkin A.A., Mozolev V.V., Mostovoy G.E. Otsenka resursa uglerod-uglerodnykh tormoznykh diskov aviakoles s uchetom evolyutsii mekhanicheskikh svoystv materiala [Estimation of a resource carboncarbon brake disks of aviawheels with account of evolution of mechanical properties of a material]. Materialy 77-y Mezhdunarodnoy nauchno-tekhnicheskoy konferentsii AAI «Avtomobile- $i$ traktorostroenie $v$ Rossii: Prioritety razvitiya i podgotovka kadrov. Kniga 5. Moscow, Moskovskiy gosudarstvennyy tekhnicheskiy universitet «MAMI», 2012, pp. 93-115.

4. Dvoretskiy A.E., Tashchilov S.V., Fadeev V.A. O mekhanicheskom unose uglerodnykh materialov [On mechanical ablation of carbon materials]. Kosmonavtika i raketostroenie, 2016, no. 2 (87), pp. 81-87.

5. Rehkopf J.A. Automotive carbon fiber composites. From evolution to implementation. SAE International, 2011, 128 p.

6. Uusitalo K. Designing in carbon fibre composites. Chalmers university of technology. Gothenburg, Sweden, 2013, $119 \mathrm{p}$.

7. Beylina N.Yu. Strukturnye preobrazovaniya pekov pri vzaimodeystvii s uglerodnymi napolnitelyami [Structural transformations of pitches at interaction with carbon fillers]. Abstract of Doctor's degree dissertation. Moscow, 2000, 53 p.

8. Malko D.B. Sposoby sovershenstvovaniya tekhnologii obemno-armirovannykh uglerod-uglerodnykh kompozitsionnykh materialov [Ways to improve the volumetric technology-reinforced carbon-carbon composite materials]. Abstract of Ph.D. dissertation. Moscow, 2000, 31 p.

9. Vetoshkin S.V., Dolgodvorov A.V., Syromyatnikova A.I. Issledovanie obemnoy mikrostruktury konstruktsionnogo uglerod-uglerodnogo kompozitsionnogo materiala i sozdanie kompyuternoy 3D-modeli issleduemogo obraztsa [Research of microstructure of structural carbon-carbon composite and the creation of computer 3D-model of the sample studied]. PNRPU Aerospace engineering bulletin, 2014, no. 37, pp. 202-221.

10. Morgan P. Carbon fibers and their composites. Boca Raton, Taylor \& Francis, 2005, 1153 p.

11. Chernenko D.N., Beylina N.Yu., Chernenko N.M. Izmenenie svoystv uglerodnykh volokon pri vysokotemperaturnoy obrabotke [Changing the properties of carbon fibers in high temperature treatment]. Uchastie molodykh uchenykh $v$ fundamentalnykh poiskovykh i prikladnykh issledovaniyakh po sozdaniyu novykh uglerodnykh i nanouglerodnykh materialov: Shkola-seminar molodykh uchenykh Tsentralnogo regiona. October 2-3, 2013, Andreevka, 2013, p. 48-51.

12. Manocha L.M, Manocha S. Co-graphitization of fibers and matrix in carbon-carbon composites with controlled interfaces. Ceramic Engineering and Science Proceedings, 2002, vol. 23, no. 3, pp. 411-418

13. Khokhlova G.P., Barnakov Ch.N., Khitsova L.M., Malysheva V.Yu., Ismailov Z.R. Osobennosti termoprevrashcheniya kamennougolnogo peka $\mathrm{v}$ usloviyakh nizkotemperaturnoy kataliticheskoy grafitatsii pri raznykh rezhimakh termoobrabotki [Features of thermal transformations of coal tar pitch in a low-temperature catalytic graphitization at different modes of heat treatment]. Vestnik Kuzbasskogo gosudarstvennogo tekhnicheskogo universiteta, 2014, no. 1 (101), pp. 89-94.

14. Trubin F.V., Dokuchaev A.G., Chunaev V.Yu. Issledovanie vliyaniya protsessov vysokotemperaturnoy obrabotki na svoystva uglerod - uglerodnykh materialov, prednaznachennykh pod parofaznoe silitsirovanie [Investigation of the effect of high temperature treatment process on the properties of carbon - carbon materials designed for vapor phase siliconizing]. Izvestiya vysshikh uchebnykh zavedeniy. Seriya "Khimiya $i$ khimicheskaya tekhnologiya», 2012, no. 6, pp. 48-51. 
15. Malafeev A.S., Voskresenskiy B.A., Gulyaykin A.P., Nechaev I.A., Valeev R.R., Krasnov L.L. Teplozashchitnyy erozionnostoykiy uglerod-uglerodnyy kompozitsionnyy material i sposob ego polucheniya [Heatshielding anti-erosive carbon-carbon composite material and a way of its manufacturing]. Patent Rossiiskaia Federatsiia, 2386603, MPK C 04 B 35/52, C 01 B 31/00, C 08 J 5/04. /; 2007139204/04(042911), 20.04.2010.

16. Marković V. Use of coal tar in carboncarbon composites. Fuel, 1987, vol. 66, no. 11, pp. 1512-1515.

17. Obzor rynka peka kamennougolnogo v SNG [The review of the market of coal tar pitch in the CIS]. Moscow, OOO IG «Infomayn», 2015, 105 p.

18. Barnakov Ch.N., Vershinin S.N., Khokhlova G.P., Samarov A.V. Vliyanie tallovogo masla i ultrazvukovoy obrabotki na poluchenie peka iz smoly polukoksovaniya ili antratsenovoy fraktsii [Influence of tall oil and the ultrasonic treatment for a pitch or resin semicoking anthracene fraction]. Koks $i$ khimiya, 2015, no. 10, pp. 33-37.

19. Marakushina E.N., Kuznetsov P.N., Buryukin F.A., Kositsyna S.S. Poluchenie alternativnogo svyazuyushchego peka metodom termokhimicheskoy pererabotki ugley [Receiving an alternative binder pitch by thermochemical processing of coal]. Fundamentalnye issledovaniya, 2015, no. 12 (part 3), pp. 474-479.

20. Beylina N.Yu. Osobennosti primeneniya uglerodnykh nanostruktur v matritsakh kompozitsionnykh materialov [Features of application carbon nano-structures in matrixes of composite materials]. Sbornik tezisov dokladov Devyatoy Mezhdunarodnoy konferentsii «Uglerod: fundamentalnye problemy nauki, materialovedenie, tekhnologiya». Moscow, Troitsk, 2014, pp. 53-57.

21. Sukhoruchenkov B.A. Analiz maloy vyborki. Prikladnye statisticheskie metody [Analysis of a small sample. Applied statistical methods]. Moscow, Vuzovskaya kniga, 2010, 384 p.

22. Korn G., Korn T. Spravochnik po matematike. Dlya nauchnykh rabotnikov i inzhenerov [Mathematical handbook for scientists and engineers]. Moscow, Nauka, 1973, 832 p.

\section{Об авторах}

Шендеров Илья Борисович (Пермь, Россия) - доктор технических наук, заместитель генерального директора по науке АО «Пермский научно-исследовательский технологический институт» (614990, г. Пермь, ул. Героев Хасана, д. 41, e-mail: ishenderov@pniti.ru).

Воскресенский Борис Анатольевич (Пермь, Россия) - заместитель генерального директора по спецтехнике, начальник научно-производственного центра углеродных композиционных материалов АО «Пермский научно-исследовательский технологический институт» (614990, г. Пермь, ул. Героев Хасана, д. 41, e-mail: info@pniti.ru).

Гуляйкин Александр Павлович (Пермь, Россия) - главный технолог научно-производственного центра углеродных композиционных материалов АО «Пермский научно-исследовательский технологический институт» (614990, г. Пермь, ул. Героев Хасана, д. 41, e-mail: info@ pniti.ru).

Сысоева Ирина Вячеславовна (Пермь, Россия) - начальник сектора научно-производственного центра углеродных композиционных материалов АО «Пермский научно-исследовательский технологический институт» (614990, г. Пермь, ул. Героев Хасана, д. 41, e-mail: info@pniti.ru).

\section{About the authors}

Iliia B. Shenderov (Perm, Russian Federation) - Doctor of Technical Sciences, Deputy General Director for Science, JSC «Perm Scientific Research Technological Institute» (41, Geroev Khasana st., Perm, 614990, Russian Federation, e-mail: ishenderov@pniti.ru).

Boris A. Voskresenskii (Perm, Russian Federation) - Deputy General Director for Special Equipment, Chief of the Research-and-production Center of Carbon Composite Materials, JSC «Perm Scientific Research Technological Institute» (41, Geroev Khasana st., Perm, 614990, Russian Federation, e-mail: info@ pniti.ru).

Aleksandr P. Guliaikin (Perm, Russian Federation) - Main Technologist of the Research-andproduction Center of Carbon Composite Materials, JSC «Perm Scientific Research Technological Institute» (41, Geroev Khasana st., Perm, 614990, Russian Federation, e-mail: info@pniti.ru).

Irina V. Sysoeva (Perm, Russian Federation) - Chief of Sector of the Research-and-production Center of Carbon Composite Materials, JSC «Perm Scientific Research Technological Institute» (41, Geroev Khasana st., Perm, 614990, Russian Federation, e-mail: info@pniti.ru). 